\title{
Forced Traction: An Error
}

\section{MP Patel*, BS Rathod and BN Suthara}

Department of Gynaecology \& Obstetrics, Sardarkrushinagar Dantiwada Agricultural University, India

Received: 眥 April 27, 2018; Published: 些 May 18, 2018

*Corresponding author: Patel Mayank, Department of Gynaecology \& Obstetrics, Sardarkrushinagar Dantiwada Agricultural University, India

Keywords: Dystocia, Incomplete Dilatation of the Cervix, Abnormal Traction; Congenital Hypoplasia; Birth Canal; Vulva; Vulvar Orifice; Lumbo-Sacral Position; Dexamethasone; Placenta

\section{Introduction}

Immediate cause of dystocia requires certain preparations and precautions so that if dystocia occur, prompt handling may prevent injury or death of either or both the dam and fetus. The maternal causes of dystocia are largely those factors that produce a narrowing or stenos are of the birth passage or prevent the normal entrance of the fetus into the birth canal. Robert [1] stated that hereditary or congenital hypoplasia of the birth canal or vulva; compression or stenos is of the cervix, vagina, or vulva by indurations caused by scars and connective tissue usually from injuries at previous parturitions; failure of the cervix to dilate can leads to maternal dystocia.

\section{Case History and Observations}

A five year old, full term pregnant, Kankrej cow of her second parity was presented to the Jalaram Gauseva Kendra, Bhabhar, district Banaskantha. The history revealed that the cow was in labour since last day. The true water bag was ruptured before $3 \mathrm{hrs}$ and progress of two hind limbs was noticed at vulvar orifice. The owner has made efforts to deliver the fetus by application of traction at both hind limbs. The cow was in lateral recumbency with eversion of vagina and the fetus was presented at external so in posterior longitudinal presentation, lumbo-sacral position with the hind limbs protruding out of the cervix (Figure 1).

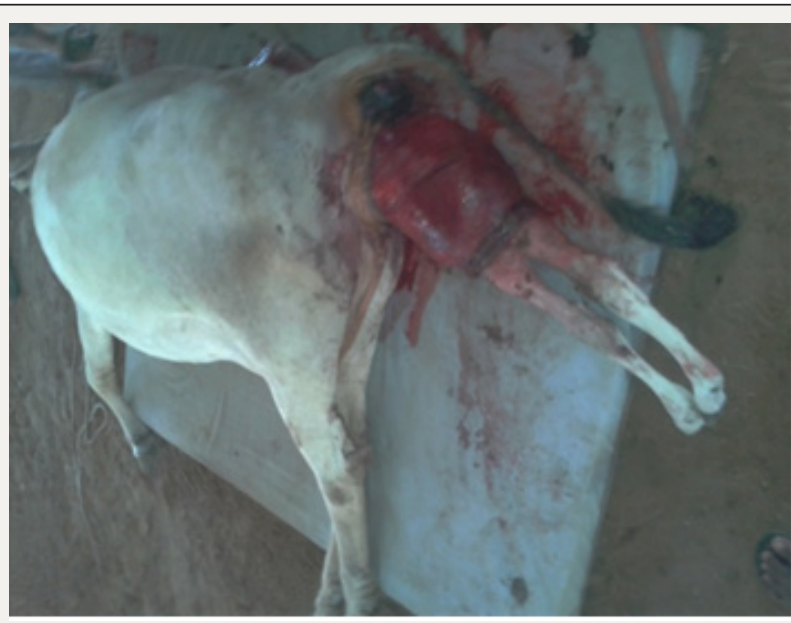

Figure 1: Prolapse of the vagina at the time of parturition in Kankrej cow.

\section{Treatment}

The cow was brought on the dorsal recumbancy and epidural anaesthesia was induced with $6 \mathrm{ml}$ of $2 \%$ lignocain hydrochloride.
Inj. Dexamethasone $5 \mathrm{ml}$ was injected before the intervention. The dorsal aspect of the external so of the cervix was incised to widen the passage and calving rope was applied at the pastern joint of 
both hind limbs. The cervix was hold at the external so and gentle forced traction was applied on the calving rope. The dead male fetus was delivered (Figure 2). The placenta was removed manually, the incision was sutured using chromic catgut \#1 and the prolapsed mass was relocated as per standard procedure. Four boluses of
Oxytetracycline hydrochoride were placed in uterus. The cow was treated with Inj. DNS- 4 lit. I/v, Inj. RL-2 lit. I/v, Inj. Analgine-15ml $\mathrm{I} / \mathrm{m}$, Inj.Oxytetracycline Hydrochloride $40 \mathrm{ml} \mathrm{I/v}$ and Injection Chlorpheneramine maleate $10 \mathrm{ml} \mathrm{I} / \mathrm{m}$. The cow could not survive and succumbed to death after $3 \mathrm{hrs}$ of the treatment.

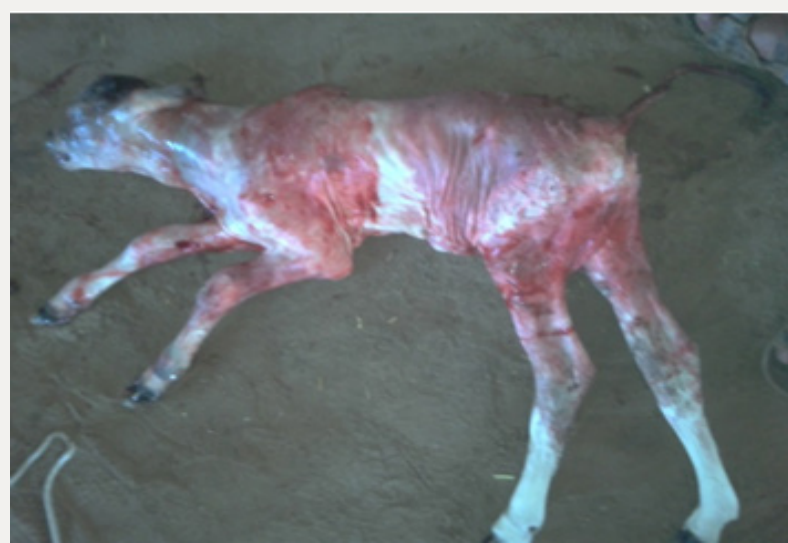

Figure 2: Dead delivered male fetus.

\section{Discussion}

Robert [1] stated that when the balance between fetus size and pelvic or genital tract diameter gets upset, the dystocia results. When traction is applied the operator should constantly watch, examine and direct the progress of fetus by instructing his assistance when to apply traction, when it should cease, and in what direction it should be applied. If the progress of the fetus through the birth canal ceases, traction should be discontinued and the fetus and the birth canal should be carefully examined to determine the cause of the obstruction. The cause should be overcome or corrected before exerting further traction. If the patient is straining, traction should be applied principally during expulsive efforts. These both aids the withdrawn of the fetus and to some extent prevents the fetus dragging parts of the uterus and vagina along with it. To avoid the lacerations and ruptures of the soft structures of the birth canal time should be allowed for dilatation of the birth canal as the fetus advances. In the present case prolapse of the vagina might have occurred due to applying extreme expulsive efforts while the cervix was incompletely dilated and the fetus might have died due to asphyxia. The death of the cow might have occurred due to hypovolaemia resulted into shock.

\section{References}

1. Robert SJ (1971) Veterinary obstetrics and genital diseases. $2^{\text {nd }}(E d n)$, CAB publisher and distributors, India pp. 227-253.
This work is licensed under Creative Commons Attribution 4.0 License

\section{Submission Link:}

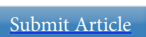

DOI: $10.32474 / C D V S .2018 .01 .000114$

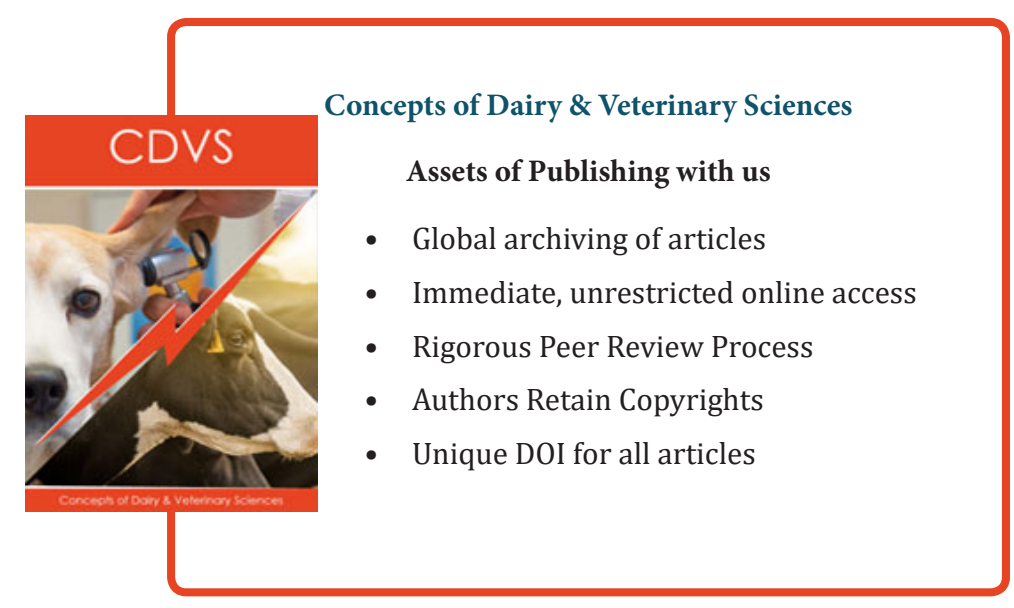

